\title{
Que desenho ensinar? Análise de discursos das revistas pedagógicas de São Paulo no início do século XX
}

Claudia Regina Boen Frizzarini

Universidade Federal de São Paulo - UNIFESP/Guarulhos

claudiafrizzarini@gmail.com

\section{Deoclecia de Andrade Trindade}

Universidade Federal de São Paulo - UNIFESP/Guarulhos

deo.clecia.1@gmail.com

\section{Maria Célia Leme da Silva}

Universidade Federal de São Paulo - UNIFESP/Diadema

mcelialeme@gmail.com

\begin{abstract}
Resumo
O presente artigo tem como objetivo analisar os discursos proferidos em revistas pedagógicas paulistas no início do século XX em diálogo com debates internacionais sobre o ensino de desenho para o curso primário, na intenção de criticar o ensino do desenho geométrico e promover o desenho ao natural. Com finalidades próprias que buscam desenvolver educar os olhos e a mão, promover a prática de medidas e favorecer um ensino profissional, o desenho ao natural, conjuntamente ao método intuitivo de ensino, modifica a cultura escolar com seu ensino analítico e artístico, desvinculado da cópia e da precisão. Tudo indica que a organização da classe artística é determinante na introdução do desenho ao natural na escola primária brasileira, em sintonia com o debate internacional.
\end{abstract}

Palavras-chave: Ensino de desenho. Escola primária. Finalidades. São Paulo. Circulação internacional.

\section{Wich teach drawing? Discourse analysis of pedagogical journals of São Paulo in the early 20th century}

\footnotetext{
Abstract

This article aims to analyze the speeches delivered in São Paulo pedagogical journals at the beginning of international discussions with dialogue in the 20th century on the drawing of education to primary school, with the intention of criticizing the geometric drawing education and to promote the drawing to the natural. With own purposes seeking to develop educating the eyes and the hand, promote practical measures and promoting a vocational education, drawing the natural together the intuitive method of teaching change the school culture with its analytical and artistic education, unbound copy and accuracy. Everything indicates that the organization's artistic community is
} 
crucial to introduce the drawing to the natural in Brazilian primary school in line with the international debate.

Keywords: Drawing education. Elementary school. Purposes. São Paulo. International circulation.

\section{Considerações iniciais}

O presente estudo ${ }^{1}$ tem o intuito de analisar os discursos sobre o ensino de desenho que circulam nas revistas pedagógicas paulistas do início do século XX, pautados em discussões internacionais. O período compreendido neste artigo corresponde ao momento em que se balizam as primeiras iniciativas republicanas de institucionalização da escola paulista com um modelo produzido por uma pedagogia.

Centrada na reprodução de um modelo escolar por meio de estratégias de produção de visibilidade de práticas exemplares, essa lógica punha em cena dispositivos de propagação e implantação de "bons moldes" e de homogeneização das práticas docentes. Estratégias de formação, como as demonstrações de práticas docentes na Escola-modelo, os relatórios de inspeção e a divulgação impressa de "modelos de lições" em livros e revistas dirigidos a professores (CARVALHO, 2011, p. 185, grifos nossos).

A reforma da instrução pública paulista, iniciada em 1890, vem oficializar, institucionalizar e sistematizar um conjunto de aspirações educacionais do final do Império brasileiro que convergem para a busca da cientificidade na educação da criança, demarcando a hegemonia dos métodos intuitivos e analíticos para o ensino de todas as matérias (MORTATTI, 2000).

Estudos desenvolvidos por Leme da Silva (2014a, 2014b), a partir de normatizações, manuais didáticos e revistas pedagógicas de São Paulo, retratam a estreita ligação entre os saberes de geometria e de desenho ao longo do século XIX. Os traçados à mão livre de figuras geométricas assumem-se como suporte e reforço para o ensino de geometria, assim como papel condutor na metodologia do ensino do desenho. Entretanto, no início do século XX, constata-se uma ruptura entre as matérias de Geometria e de Desenho²:

Uma nova fase se inicia para esses dois saberes escolares [...]. Certamente a chegada da intuição, da lição das coisas e da importância de se observar as coisas contribuem para um novo método do Desenho, que prioriza os objetos reais, de interesse dos alunos e de abandono de aspectos abstratos da geometria (LEME DA SILVA, 2014a, p. 72).

\footnotetext{
${ }^{1}$ Este artigo representa resultado parcial do projeto "A dimensão prática e a escolarização dos saberes elementares geométricos", coordenado pela prof. Dra. Maria Célia Leme da Silva com financiamento FAPESP sob processo ${ }^{\circ}$ 2014/24220-2.

${ }^{2}$ As matérias de ensino serão designadas ao longo deste artigo com a primeira letra em maiúscula, por exemplo, Desenho. Quando mencionado com todas as letras minúsculas refere-se a um saber.
} 
No entanto, a partir do desenvolvimento de projeto de âmbito nacional ${ }^{3}$, novas revistas são inventariadas e retoma-se a questão sobre o ensino de desenho no início do século XX, com vistas a analisar como as propostas das revistas para o ensino de desenho dialogam com as discussões internacionais e os princípios da Pedagogia Moderna, ou seja, quais as finalidades postas na nova concepção de desenho, desligado da geometria.

Vale considerar que o ensino de desenho, assim como outros saberes matemáticos do curso primário, não se organiza de forma disciplinar como no curso secundário: identifica-se o ensino de desenho em diferentes matérias escolares, como Geometria, Trabalhos Manuais e até mesmo Aritmética. Desse modo, as seções a seguir abordam os distintos ensinos de desenho discutidos nas revistas paulistas que não somente compunham o ensino da matéria escolar Desenho, mas também as diversas outras que utilizam essa construção.

\section{O desenho geométrico e o desenho natural: momento de transição}

No início do século XX, os artigos das revistas pedagógicas de São Paulo trazem à cena duas propostas distintas para o ensino de desenho no curso primário, o desenho ao natural e o desenho geométrico. As críticas são direcionadas ao desenho geométrico, no contraponto com a defesa do método do desenho ao natural.

O artigo "A Natureza, mestre de desenho. Bancarrota do ensino oficial", assinado por Jorge Moreau (1906) e publicado na Revista de Ensino ${ }^{4}$ de São Paulo com a nota "especialmente traduzido do Monde ilustre para a Revista pelo Dr. Ruy de Paula Souza, professor de francez na Escola Normal", indica claramente a transição do ensino de desenho em nível internacional. O artigo divide-se em duas partes: a primeira de críticas ao método geométrico e a segunda, com propostas e defesa do método do desenho ao natural.

Em relação às críticas, o artigo menciona a luta entre dois métodos de ensino de desenho opostos, propostos na França, na segunda metade do século XIX, o método geométrico do escultor Guillaume e o método natural ou de desenho à mão livre do filósofo Ravaisson. Naquela altura, o método geométrico vence, atravessa o Atlântico e chega aos EUA, causando os mesmos problemas que na França: ao final dos estudos, os alunos não sabem desenhar. O fracasso do método geométrico é objeto de discussão na Exposição de Chicago de 1894. Em paralelo à bancarrota do

\footnotetext{
${ }^{3} \mathrm{O}$ projeto a que se refere intitula-se “A Constituição dos Saberes Elementares Matemáticos: a Aritmética, a Geometria e o Desenho no curso primário em perspectiva histórico-comparativa, 1890-1970”, desenvolvido pelo GHEMAT desde 2012 sob coordenação do Prof. Dr. Wagner Rodrigues Valente com apoio do CNPq, organiza e disponibiliza as fontes de pesquisa no repositório virtual (https://repositorio.ufsc.br/xmlui/handle/123456789/1769).

${ }^{4}$ A Revista de Ensino circulou de 1902 a 1919 (o último número é relativo ao período de julho a dezembro de 1918, mas é publicado em 1919) e foi uma iniciativa da Associação Beneficente do Professorado Público de São Paulo. Em 1905, a publicação perdeu a subvenção oficial, retomada em 1911 (SHIEH, 2010).
} 
modelo oficial, a exposição de desenhos de alunos de oito anos de uma única escola americana, que se recusa a seguir o método geométrico, surpreende a todos e é considerado o pontapé para a reforma do ensino, liderada por M. J. Liberty Tadd, promovendo em seguida o estudo direto do desenho ao natural.

No que diz respeito à defesa do novo método, a estratégia de convencimento do método do desenho ao natural está nas notas sobre o Congresso Internacional de Desenho, realizado na Suíça, em Berne, no ano de 1904 e que conclui como resolução para o ensino de desenho no curso primário:

Considerando que a evolução da creança regula todo o ensino racional; que o desenho deve reflectir pelo seus efeitos o mundo onde vivemos; que elle tem por objecto immediato a compehensão e a representação das apparencias visiveis; que elle tem todos os caracteres de uma lingua viva; que seu uso, como nesta, deve ser facil, pela obediencia immediata da mão ao pensamento; que elle deve, como fito superior, levar ao conhecimento do bello na natureza e na arte (MOREAU, 1906, p. 20).

O artigo veiculado na Revista de Ensino de São Paulo de 1906 endossa a mudança significativa apresentada pelo programa de ensino paulista oficializado em $1905^{5}$, no qual os conteúdos das matérias de Geometria e de Desenho são visivelmente desvinculados. Mostra ainda a sintonia do estado de São Paulo no debate internacional, reforçando seu papel de liderança na implementação da escola primária sob a égide da Pedagogia Moderna.

O programa de ensino paulista de 1905 dedicado às escolas modelo e aos grupos escolares é aprovado pelo Decreto 1281 de 24 de abril de 1905. A dissertação de Shieh (2010) permite inferir que os redatores do programa seriam Oscar Thompson (também redator do programa de 1894) e Horacio Lane (diretor da escola Americana). Ambos indicam a relação do programa com a Pedagogia Moderna, visto que Lane é um dos representantes da Escola Americana no Brasil, uma das primeiras instituições brasileiras a adotar o método intuitivo de ensino. Além disso, Lane e Thompson, os "candidatos" a elaborar o programa de 1905, estiveram presentes na Exposição Internacional de St. Louis nos EUA em 1904 (SANTOS, 2011), o que corrobora a apropriação de discussões internacionais no programa de Desenho.

Os pesquisadores Renaud D’Enfert e Daniel Lagoutte (2004) destacam a importância das exposições universais no progresso das nações estrangeiras e vulgarização do ensino de desenho, transformando tal ensino em causa nacional: a supremacia artística do país como vitalidade de sua

\footnotetext{
${ }^{5}$ O ensino de desenho no programa paulista de 1905 recebe novo enfoque, não se utiliza mais dos objetos geométricos como em 1894. Esse novo desenho é introduzido pelo estudo de objetos simples do cotidiano, tais como plantas e animais, e somente no terceiro e quarto anos propõe a reprodução de modelos geométricos e de sólidos, entretanto, esses são feitos de modo simples, sem o auxílio de instrumentos, todos feitos à mão livre. Desse modo, a matéria Geometria, no programa paulista de 1905, compreende totalmente as construções e para essas utiliza os instrumentos régua, transferidor e esquadro (FRIZZARINI, 2014).
} 
economia estão em jogo. Beguery (2003) endossa a posição de D’Enfert e Lagoutte e salienta que a efervescência das exposições universais suscita a retomada da problemática e debates sobre a finalidade do desenho. Particularmente, a exposição de Londres (1851) apresenta a criação de instituições como o South Kensigton Museum, assim como a confrontação de desenhos de crianças de diferentes países. Depois de um século em que o desenho esteve ao lado da cientificidade, outra concepção de desenho é posta em discussão.

Como já visto, os ecos sobre as propostas de ensino debatidas nos Congressos Internacionais de Desenho não demoram a circular no Brasil. O segundo número da Revista de Ensino publica novo artigo, assinado por Renée Pingrenon (1906), também traduzido pelo professor de francês da escola Normal, Ruy de P. Souza, intitulado "A Natureza, mestre de Dezenho Segundo Congresso Internacional - Berne, 26 de agosto de 1904”, em que apresenta um relatório sobre o evento, com as delegações que participaram e as seções de trabalho.

Uma vez mais, no ano de 1906, o artigo de Persio da Cunha Canto ${ }^{6}$ reitera as críticas ao desenho geométrico em defesa do ensino do desenho ao natural nas escolas primárias:

Até hoje todos os methodos têm dado resultados completamente nullos. Fica-se unicamente imbuído nessas figuras geométricas (referimos ao methodo geométrico) que absolutamente não educam a mão e a vista. [...] Precisamos de um methodo por meio do qual se possa desenhar qualquer objecto que se nos apresente - é o desenho ao natural. Elle deve obedecer á mão e vivamente ao pensamento (CANTO, 1906, p.768).

$\mathrm{O}$ artigo, assim como os demais, também usa a Exposição de Chicago como respaldo de sua reprovação aos métodos anteriores e aponta o desenho ao natural como propulsor verdadeiro da educação da mão e da vista. Assim, o apelo ao educar a mão e a vista assume o papel de finalidade principal do ensino de desenho no estado de São Paulo.

\section{O método de ensino de desenho da Pedagogia Moderna: desenho ao natural}

Mesmo após a introdução do desenho ao natural no programa de 1905, múltiplos argumentos são observados nas revistas pedagógicas de São Paulo corroborando em favor da defesa do desenho ao natural, de modo a reforçar e consolidar a nova abordagem.

A associação do desenhar como linguagem de expressão é uma das indicações da importância do ensino de desenho em consonância com seu novo método, o natural, um desenho articulado de forma simples, entendido como um saber elementar, em que "a arte do desenho é uma língua que é preciso saber falar" (FREITAS, 1911, p. 127). Jorge Moreau também versa sobre a

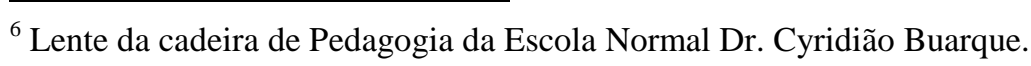


constatação do desenho como uma língua, cita o Sr. Guébin ${ }^{7}$ e Emile Reiber ${ }^{8}$ estabelecendo analogia entre a língua materna e as aulas de desenho: "parece-lhe natural que a creança rabisque antes de desenhar correctamente, do mesmo modo que ella balbucia antes de falar correntemente" (MOREAU, 1906, p. 20).

O artigo "Theoria e pratica do desenho" de N.M.E.N.S (19013) estabelece a necessidade de, independente do saber em questão, estar em sintonia ao método analítico, considerado como método geral. Diz o autor: "antes de mais nada lembremo-nos de que os méthodos de desenho estão filiados aos méthodos geraes do ensino. Como acontece com a leitura, devemos partir do todo para a parte, isto é, devemos adoptar o méthodo analytico para o seu ensino" (N.M.E.N.S., 1913, p. 24).

Empregar o método analítico ao desenho significa que a marcha do ensino segue do todo para a parte. Fica evidente o contraponto entre o desenho natural e o já descartado desenho geométrico, que segue a ordem dos assuntos, da geometria plana para a espacial, criticada pelo mesmo autor: "linhas simples e ângulos não significam coisa alguma para a intelligencia de uma criança; são como as letras e syllabas dos méthodos de leitura antigos, que seguem os processos de soletração e syllabação" (Ibidem, p. 25).

Ainda em relação ao método, outro ponto de destaque nos artigos é a importância pela figura natural, objeto real para ser reproduzido, e não o uso de figuras ou desenhos prontos. Teodoro Braga ${ }^{9}$ faz um apelo no artigo publicado na Revista Escolar ${ }^{10}$, em 1926, de proibir de maneira formal o uso da estampa na instrução publica, pois, segundo o autor,

Copiar de outrem é escravizar a alma das crianças; é forçar a reproduzir a fórma aplanada dum corpo que tem relevo, tirando assim ao cerebro o direito de observar, raciocinar e criticar. Já a estampa é uma reprodução errada por si mesma, pela simples razão de o ter feito através dum temperamento pessoal, quasi sempre commercial (BRAGA, 1926, p. 48).

O desenho ao natural preza pela construção do desenho à vista do objeto, em que não se corre o risco de mandar as crianças desenharem objetos fora de seu cotidiano, como Braga (1926, p. 49) propõe, "façamos obra brasileira para brasileiros".

\footnotetext{
${ }^{7}$ Inspector principal do ensino de desenho na cidade de Paris.

${ }^{8}$ Autor de "O desenho ensinado pela escrita" (Paris, 1879): le dessin enseigné par l'écriture.

${ }^{9}$ Teodoro José da Silva Braga, pintor, historiador da arte, ilustrador, decorador e professor. Inicia sua carreira de pintor ainda estudante da Faculdade de Direito do Recife, onde se forma em 1893. Em 1921, fixa residência em São Paulo, onde atua como professor no Instituto de Engenharia Mackenzie e na Escola de Belas Artes. Assume o cargo de diretor da escola, ocupando-o até seu falecimento. Entre as atividades empreendidas em São Paulo, destaca-se a criação da Escola Brasileira de Arte, que oferece aulas de música, desenho e pintura para crianças e adolescentes. Publica, em 1942, o livro Artistas Pintores do Brasil, além de livros técnicos de desenho e artigos em jornais e revistas. Disponível em <http://enciclopedia.itaucultural.org.br/pessoa10853/theodoro-braga>, acesso em 28 set. de 2015.

${ }^{10}$ A Revista Escolar começa a circular em janeiro de 1925, sete anos após o fim da Revista de Ensino e segue até setembro de 1927. De forma geral, os colaboradores do periódico ocupam posições de destaque na hierarquia do sistema púbico paulista (SHIEH, 2010).
} 


\section{As finalidades do ensino do desenho natural}

Os artigos comentados nas seções anteriores, de crítica ao ensino geométrico e as discussões do desenho natural como um método de ensino, já indicam a finalidade principal atribuída à nova concepção do desenho ao natural - educar a vista e a mão.

Discursos internacionais nas revistas paulistas apontam a resolução tirada no Congresso de Berne, em 1904, em que salientam que o desenho tem por objetivo imediato a compreensão e a representação das aparências visíveis e a obediência da mão ao pensamento (MOREAU, 1906). Ressaltam ainda a influência das ideias de Rousseau na reforma proposta por Tadd, do desenho ao natural, com destaque para a vista:

De todos os sentidos é a vista o mais dificilmente separavel dos raciocinios do espirito; é preciso, pois, muito tempo para aprender a ver; é preciso ter, por muito tempo comparado a vista com o tacto para habituar o primeiro destes sentidos e das distancias: sem o tacto, sem o movimento progressivo, a vista, a mais penetrante, não poderia dar-nos ideia alguma de distancia [...] (ROUSSEAU apud MOUREAU, 1906, p. 18).

O artigo que descreve o Congresso Internacional de Desenho de 1904, assinado por Renée Pingrenon, convida o leitor a refletir sobre o papel da mão e do olho no ensino de desenho.

Ora, reflicta-se bem: apprender a gozar de todas as vantagens do sentido da vista; exercitar-se desde a meninice a fazer trabalhar paralelamente a mão, o olho, o cérebro, de um modo progressivo, em exercicios habilmente dirigidos; isto dará forçosamente uma instrução ao mesmo tempo intelectual para as necessidades normaes da existencia humana (PINGRENON, 1906, p. 58).

O artigo "O desenho na escola" de A. R. (1907) alinha-se com os demais na corrente pelo desenho ao natural, reitera, uma vez mais, as deliberações do Congresso de Desenho de 1904 em Berne e considera o ensino do desenho como propulsor da cultura da sensibilidade estética, em acordo com os preceitos de Rousseau:

Que a criança meça com os olhos; que tenha sempre deante dos olhos o próprio original e não o papel que o representa; que nada trace de memoria, na ausência dos objetos; mais tarde, então, a vista será justa e a mão flexível e alcançarão, por fim, a elegância dos contornos e o traço leve (ROUSSEAU apud A.R., 1907, p. 27).

Vista justa e mão flexível são os fins do ensino do desenho ao natural. A sensibilidade e a elegância se formam a partir do treino do olhar, expresso pela medida realizada com os olhos e pelo desenvolvimento de habilidade prática nos traçados leves. 
Ramon Roca Dordal ${ }^{11}$, professor espanhol atuante nas escolas primárias brasileiras, publica em 1912 o artigo "O ensino de desenho - observações geraes - methodo e processos", no qual enfatiza a finalidade do ensino do desenho como "educar a vista, habituando a ver com justeza e representar com facilidade o objecto visto" (DORDAL, 1912, p. 68), em que representar com facilidade pode ser entendida como educar a mão. Um ano depois, em 1913, é a vez de N.M.E.N.S expor seu ponto de vista, "o desenho não é tanto uma questão de arte, como é uma questão de utilidade. Tem por fim educar a vista como o trabalho manual tem por fim educar a mão" (N.M.E.N.S., 1913, p. 26).

O autor ressalta a educação da vista como função do desenho e destina o educar a mão para os trabalhos manuais, talvez por não exigir a perfeição nos traçados, pois

Pouco importa as imperfeições ou deformidades que invariavelmente acompanham as primeiras provas. O que se quer é educar a vista e desenvolver a intelligencia. A escola não visa preparar artistas, porém educar o cidadão para a vida prática (N.M.E.N.S., 1913, p. 25).

A não perfeição nos traçados é igualmente sublinhada por outros autores. Ramon Dordal (1912) reafirma que o desenho não tem por fim formar artistas e sim desenvolver o gosto e educar a vista e, desta forma, os alunos que pouco conseguem aparentemente não deixam de exercitar-se e assim melhorar os seus meios de percepção. Freitas (1911) comenta que nas exposições de desenho que visitou nos grupos escolares paulistas, encontrou poucos desenhos de alunos do $1^{\circ}$ e $2^{\circ}$ ano escolar, por talvez estarem longe de dar uma ideia do modelo, mas que tal atitude é um erro, pois "a questão, nessas classes, não é saber si as crianças fazem bons desenhos, mas sim si desenvolvem as suas faculdades. Devemos deixa-las rabiscar muito papel [...]” (FREITAS, 1911, p. 129).

Em síntese, parece ser evidente no conjunto de artigos a caracterização da finalidade do desenho ao natural como prática de educar o olho e a mão, a habilidade desenvolvida no exercício da observação e do traçado. O resultado final não é o mais significativo e sim a prática do desenhar como faculdade a ser desenvolvida.

\section{Práticas de medidas: educação da vista?}

Ao considerar o desenho natural um ensino cuja finalidade é a educação da vista e da mão, aprender a medir com os olhos torna-se o exercício necessário para alcançar tal intento, ou seja, fazer medições de objetos expostos pelo olhar é o que leva a educação da vista.

\footnotetext{
${ }^{11}$ Ramon Roca Dordal nasceu em 1854 na Espanha e veio ao Brasil com 19 anos, trabalhou como desenhista na estrada de ferro do Rio de Janeiro e como tipógrafo no Jornal do Commercio. Em 1886 matriculou-se na Escola Normal de São Paulo e depois de diplomado ocupou a $1^{\mathrm{a}}$ cadeira de Itatiba e posteriormente tornou-se $1^{\mathrm{o}}$ diretor do Grupo Escolar Cel. "Júlio César", lecionou na $2^{\text {a }}$ escola modelo de São Paulo, chamada "Escola Modelo do Carmo" como auxiliar de Alfredo Bresser por 10 anos. Exerceu cargo de $1^{\circ}$ Grupo Escolar do Braz e foi colaborado ativo das revistas A Eschola Publica e Revista de Ensino. Foi inspetor escolar na cidade de São Paulo até 1919 e faleceu em 1938 com 84 anos (PASQUIM, 2010).
} 
Aspecto defendido por Cymbelino Freitas (1911, p.138), "Sendo conveniente que os alumnos desenhem mais ou menos do tamanho natural (para que possam directamente verificar algum engano na proporção do desenho), é claro que as dimensões do modelo precisam não exceder as folhas de papel".

Para isso, um novo discurso propaga nas revistas, de cuidado nas escolhas de modelos a serem adotados, tendo em vista que os alunos devem, em seus primeiros exercícios, reproduzir os modelos com as medidas mais justas ao objeto real. A isso, Dordal (1912, p. 64) destaca: "dar para modelo um objeto que há de ser representado e também reduzido, é copiar do natural, mas não é dar um bom modelo aos principiantes, que antes de poderem reduzir precisam aprender a representar os objetos em seu tamanho aproximado".

Desse modo, só em seguida, após conseguir reproduzir o desenho com as dimensões do modelo original, passa-se a treinar desenhos em tamanhos menores ou ampliados. Ou seja, com uso de escalas de proporção,
A analyse do objecto a representar, isto é, a sua cuidadosa observação por parte dos alumnos é sempre necessária, mesmo que o objecto tenha de ser representado em tamanho natural.
Para ser representado em tamanho reduzido ou ampliado essa analyse augmenta ainda de importancia, convido encaminhar o alumno até a apreciação das diversas partes do objecto, fazendo idea clara de suas proporções (DORDAL, 1912, p. 68).

Como se nota, a observação constante e cuidadosa aos objetos/modelos é o aliado para medir com os olhos e consequentemente educar a vista. Para alcançar a finalidade a que se pretende no ensino do desenho natural, Moreau (1906) expõe que a criança meça com os olhos e acrescenta:

Só depois de muito andar, de muito apalpar, de muito numerar, de muito medir distancias é que se apprende a avalial-as; de um outro lado, si se medisse sempre, o sentido descansando no instrumento, não adquiriria exatidão alguma. Não deve também a creança passar de repente da medida para a avaliação; é preciso que, continuando a comparar por partes aquillo que ella não poderia comparar no conjunto, ella substitua alíquotas exactas por alíquotas de apreciação, e que, em vez de applicar sempre a medida com a mão, ella se habitue a fazer esta applicação, exclusivamente com os olhos (ROUSSEAU apud MOUREAU, 1906, p. 18, grifos nossos).

O educar a vista pelas medidas é um processo contínuo e em evolução. O aluno não nasce sabendo, o desenho natural é algo construído em fases. Entretanto, espera-se com o ensino do desenho natural na escola primária que o aluno seja apto a medir com os olhos as dimensões de qualquer objeto e que imbricado a isso consiga representar modelos, dentro dos moldes da escola que não objetiva a formação de artistas, mas sim, educar para a vida prática.

\section{Formar profissionalmente o aluno: educar as mãos?}


As medidas feitas a olho e os desenhos realizados à mão livre remetem à formação do aluno em suas vias profissionais e têm sido, desde o final do século XIX, uma das grandes finalidades da escola primária.

Nas revistas paulistas do início do século XX, o desenho ao natural é proposto como novo método para o ensino de desenho, que além de promover o sustento do espírito da criança: "póde ser mais tarde fonte de receita, ou um meio de obter maior producto do seu trabalho" (CANTO, 1906, p. 768). As lições propostas ao desenho natural por despertarem o gosto pela ordem e precisão, segundo Freitas (1911), fornecem noções gerais de exatidão, clareza e asseio, qualidades essenciais aos futuros obreiros, “[...] por fim principal preparar o melhor possivel a criança para o exercício das profissões manuaes. O desenho é indispensável para a habilidade particular do operário, para a honra industrial e proveito commercial dum paiz” (FREITAS, 1911, p. 127).

Estes preceitos identificados no desenho ao natural como auxiliador no preparo à vida profissional do aluno remetem a sua importância no ensino preliminar:

[...] a convicção de que a habilidade de desenhar precisa ser adquirida pelo alumno, como preparo indispensável, qualquer que seja o officio, arte ou ramo de conhecimento a que elle tiver de se dedicar, fizeram-se pensar em processuar esta disciplina no curso preliminar (DORDAL, 1912, p. 63).

A citação reitera a relação entre o ensino de desenho e a finalidade do curso primário neste período inicial da República brasileira, que de acordo com Souza (2000) versa sobre a formação do futuro trabalhador.

Na década de 1920, artigos de São Paulo disseminam ainda com vivacidade a proposta de desenho ao natural e sua importância na formação do trabalhador. Theodoro Braga, professor da Escola de Belas Artes com influência nas artes francesas, apresenta, em 1923 em São Paulo na Revista de Educação ${ }^{12}$, um artigo sobre o ensino de desenho em que aponta seus inúmeros estudos sobre as orientações para o ensino de tal matéria em diversos países, e exibe, ainda, relato sobre os trabalhos obtidos por algumas de suas discípulas no Collégio Pregresso Paraense, que fazem do desenho um conhecimento "útil e econômico", na reprodução do natural de um jasmim, e da confecção de uma renda com tal motivo, sendo por fim aplicada à gola de um vestido.

Assim, a proposição do desenho como um saber provedor de ensino profissional, de um oficio, é proposta desde o final do século XIX até o início do século XX, o que indica o caráter prático e funcional do ensino do desenho. Seja na promoção de desenhos para ornatos e bordados, para confecção de costuras, para auxiliar na vida prática ou subsidiar o futuro obreiro, trabalhador,

\footnotetext{
${ }^{12}$ A revista de Educação foi editada no Estado de São Paulo, entre 1921 e 1923. Órgão da antiga Escola Normal de Piracicaba e Anexas, a revista foi publicada pelos professores dessas escolas, sendo Lourenço Filho dos principais editores e idealizadores do periódico, com o objetivo de combater o ensino verbalista de mera memorização (INOUE, 2010).
} 
artista, o desenho muda seus métodos, altera suas finalidades, mas desde o início da República mantém seu propósito de fornecer um exercício de caráter prático à vida e ao futuro ofício do aluno do curso primário.

\section{Considerações finais}

A análise dos artigos que circulam nas revistas pedagógicas do estado de São Paulo no início do século XX evidencia a efervescência de um debate sobre o ensino de desenho no curso primário brasileiro no que diz respeito as suas finalidades e as orientações pedagógicas da Pedagogia Moderna.

Educar a mão e a vista são finalidades ressaltadas como de grande relevância no método do desenho natural, e desencadeiam as práticas de medidas, na promoção do desenvolvimento da vista e formar profissionalmente o aluno, no que se refere ao aprimoramento das mãos.

O método analítico, amplamente divulgado como representante da Pedagogia Moderna, pode ter contribuído para a divergência entre o desenho geométrico e ao natural, visto que a marcha do ensino entre os dois métodos de desenho são distintos. Entretanto, o aspecto de contradição ao método analítico não é recorrente nas revistas; somente um artigo o comenta, o que nos leva a crer não ser esta a razão principal debatida.

Dois pontos de vista contraditórios marcam presença significativa nos discursos. De um lado, a visão da comunidade artística, expressa pela força dos eventos internacionais, em especial, os Congressos Internacionais de Desenho, em que também se faz uso da estratégia de formação profissional de um ofício, não restrito aos artistas, mas do futuro cidadão na sociedade moderna.

De outro lado, a visão da ciência, vinculada ao modelo do desenho geométrico, aos estudos futuros da Geometria, na qual a perfeição se faz necessária por representar conceitos abstratos, tem como fim a instrução e não a formação do aluno ${ }^{13}$ visa uma preparação para um estudo propedêutico, com vista ao ensino secundário, em que os conceitos geométricos serão definidos e suas propriedades deduzidas, na ordem lógica.

Em síntese, tudo indica que a organização da classe artística é determinante na introdução do desenho ao natural na escola primária brasileira, em sintonia com o debate internacional. Demandas externas à escola, como a profissionalização e a organização dos Congressos Internacionais de Desenho, interferem e modificam uma cultura escolar estabelecida de longo tempo e as revistas pedagógicas cumprem o papel estratégico de circulação e convencimento para a adoção do desenho ao natural como ícone da Pedagogia Moderna.

\footnotetext{
${ }^{13}$ Para um estudo aprofundado sobre a instrução/formação, ver Valente (2015).
} 


\section{Referências}

A.R. O Desenho na Escola. In: Revista de Ensino, São Paulo, Anno VI, n. 3, Junho. 1907. pp. 2628. Disponível em: < http://repositorio.ufsc.br/xmlui/handle/123456789/97513 > Acesso em: 12. Set. 2015

BEGUERY, J. Le dessin: vers un problématique enseignement artistique. In: L'école republique et la question des savoirs. Enquête au coeur du Dictionnaire de pédagogie de Ferdinand Buisson. CNRS ÉDITIONS, Paris, 2003.

BRAGA, T. O Ensino de Desenho. In: Revista da Educação. São Paulo, SP: Imprensa Methodista, Anno I, n. 3, jul. 1923. pp. 307-313. Disponível em:

<https://repositorio.ufsc.br/xmlui/handle/123456789/126486>. Acesso em: 12. Set. 2015

O Ensino de Desenho nas Escolas Publicas de S. Paulo. In: Revista Escolar. São Paulo, SP: Orgam da Directoria Geral da Instrucção Pública, Anno II, n. 13, jan. 1926. Mensal. pp. 45-51. Disponível em: < https://repositorio.ufsc.br/xmlui/handle/123456789/130590>. Acesso em: 12. Set. 2015

CANTO, P. C. Desenho. In: Revista de Ensino, São Paulo, Anno IV, n. 4, janeiro. 1906. pp. $767-$ 770. Disponível em: <http://repositorio.ufsc.br/xmlui/handle/123456789/97521>. Acesso em: 12. Set. 2015

CARVALHO, M. M. C. Pedagogia Moderna, Pedagogia da Escola Nova e Modelo Escolar Paulista. In: Carvalho, M. M. C.; Pintassilgo, J. (Org.). Modelos culturais, saberes pedagógicos, instituições educacionais. São Paulo: EDUSP, 2011, pp. 187-216.

D' ENFERT, R.; LAGOUTTE, D. Un art pour tous le dessin à l'école de 1800 à nos jours. França: INRP, 2004.

DORDAL. R. R. O ensino de desenho. - Observações geraes. - Methodo e processos. In: Revista de Ensino, São Paulo, Anno XI, n. 1, Março. 1912. pp. 63-73. Disponível em: <http://repositorio.ufsc.br/xmlui/handle/123456789/97338>. Acesso em: 12. Set. 2015

FREITAS. C. Desenho do natural. In: Revista de Ensino, São Paulo, Anno X, n. 3, Dezembro. 1911. pp. 126-138. Disponível em: < https://repositorio.ufsc.br/xmlui/handle/123456789/97339>. Acesso em: 12. Set. 2015

FRIZZARINI, C. R. B. Do ensino intuitivo para a escola ativa: os saberes geométricos nos programas do curso primário paulista. 2014. 160f. Dissertação (Mestrado em Educação e Saúde) Universidade Federal de São Paulo, Guarulhos, 2014.

INOUE, L. M. A Revista de Educação (1921-1923), o nacionalismo e A Reforma de 1920: a formação dos professores em São Paulo. 2010, 118f. Dissertação (Mestrado em educação) Universidade Estadual Paulista, Faculdade de Filosofia e Ciências, Marília, 2010.

LEME DA SILVA, M. C. Desenho e geometria na escola primária: um casamento duradouro que termina com separação litigiosa. História da Educação (UFPel), v. 18, n. 42, Jan./abr. 2014a, p. $61-73$

Régua e Compasso no ensino primário? Circulação e apropriação de práticas normativas para as matérias de Desenho e Geometria. História da Educação (UFPel), v. 18, n. 44, Set./dez. 2014b, p. 79-97.

MOREAU, J. A Natureza, mestre de desenho: Bancarrota do ensino official. In: Revista de Ensino, São Paulo, Anno V, n. 1, Julho. 1906. pp. 16-21. Disponível em: < http://repositorio.ufsc.br/xmlui/handle/123456789/97515>. Acesso em: 12. Set. 2015 
MORTATTI, M. R. L. Os sentidos da alfabetização: São Paulo / 1876-1994. São Paulo: Editora UNESP, 2000.

N.M.E.N.S. Theoria e pratica do desenho. In: Revista de Ensino, São Paulo, Anno XII, n. 2, Setembro. 1913. pp. 23-30. Disponível em: <

https://repositorio.ufsc.br/xmlui/handle/123456789/97333>. Acesso em: 12. Set. 2015

PASQUIM, F. R. Ramon Roca Dordal (1854-1938) e Carlos Alberto Gomes Cardim (1875-1938) na história da alfabetização no Brasil. Revista de Iniciação Científica da F.F.C., v. v. 10, p. p.1p.14, 2010.

PINGRENON. R. A Natureza, mestre de Dezenho: Segundo Congresso Internacional. In: Revista de Ensino, São Paulo, Anno V, n. 2, Setembro. 1906. pp. 57-59. Disponível em:

<http://repositorio.ufsc.br/xmlui/handle/123456789/97514>. Acesso em: 12. Set. 2015

SANTOS, J. V. dos. As contribuições de Horace Lane na instrução pública paulista: (1890-

1910). 2011. 134 f. Dissertação (Mestrado em educação) - Universidade Estadual Paulista, Faculdade de Filosofia e Ciências, Marília, 2011.

SHIEH, C. L. O que ensinar nas diferentes escolas públicas primárias paulistas: um estudo sobre os programas de ensino (1887-1929). 2010. 184 f. Dissertação (Mestrado) - Curso de História da Educação, Faculdade de Educação, Universidade de São Paulo, São Paulo, 2010.

SOUZA, R. F. Alicerces da Pátria: História da escola primária no estado de São Paulo (18901976). Campinas, SP: Mercado de Letras, 2009.

VALENTE, W. R. Elementar. In: VALENTE, W. R.(Org.) Prática. Cadernos de Trabalho. São Paulo: Editora Livraria da Física, 2015.

ZANATTA, B. A. O Legado de Pestalozzi, Herbert e Dewey para as práticas pedagógicas escolares. Revista Teoria e Prática da Educação, v. 15, n. 1, p. 105-112, jan./abr. 2012.

Disponível em: <http://periodicos.uem.br/ojs/index.php/TeorPratEduc/article/view/18569>. Acesso em: 16 set. 2015. 